\title{
Nocturnal Hypoxemia, an Unusual Presentation of Pulmonary Endometriosis: A Case Report
}

\author{
Andre B. Zanella ${ }^{\mathrm{a}}$, Pedro P. Oliveira ${ }^{\mathrm{a}}$, Renato Seligman ${ }^{\mathrm{a}, \mathrm{b}}$, \\ Beatriz G. S. Seligman ${ }^{\mathrm{a}}$, Tania W. Furlanetto ${ }^{\mathrm{b}, \mathrm{c}}$
}

\begin{abstract}
Thoracic endometriosis syndrome is a rare condition with four main presentations: pneumothorax, hemothorax, hemoptysis, and lung nodules. We describe an incidental diagnosis of pulmonary endometriosis in a patient admitted with acute pyelonephritis, and developed acute hypoxemia and a productive cough of blood tinted sputum, on the third day of hospitalization. Her thoracic xray showed diffuse pulmonary infiltrates, and a small pleural effusion. Chest computerized tomography scan had extensive areas of ground glass opacifications scattered predominantly in the medulla of both lungs. Bronchoalveolar lavage cytology showed small groups of cells in arrays compatible with endometrial cells, which confirmed the diagnosis of pulmonary endometriosis. On the seventh day of hospitalization, after the end of her menstrual bleeding, oxygen supplementation was discontinued, and hypoxemia did not recur. A chest x-ray at the ninth day of hospitalization was normal. Pulmonary endometriosis should be considered in a patient who has unexplained episodes of nocturnal hypoxemia associated with hemoptysis, especially if there is periodicity.
\end{abstract}

Keywords: Endometriosis; Pulmonary function; Hypoxemia; Nocturnal

\section{Introduction}

Endometriosis is defined as the presence of endometrial-like

\footnotetext{
Manuscript accepted for publication July 10, 2012

${ }^{a}$ Internal Medicine Division, Hospital de Clinicas de Porto Alegre, Hospital de Clinicas de Porto Alegre, Rua Ramiro Barcelos, 2350, sala 700, 90035-003 Porto Alegre, RS, Brazil

${ }^{\mathrm{b}}$ Postgraduate Program in Medicine: Medical Sciences, Universidade Federal do Rio Grande do Sul, Rua Ramiro Barcelos, 2400, $2^{0}$ andar, 90035-003 Porto Alegre, RS, Brazil

${ }^{\mathrm{c} C}$ Corresponding author: Tania W. Furlanetto, Internal Medicine

Division, Hospital de Clinicas de Porto Alegre, Rua Ramiro Barcelos, 2350, sala 700, 90035-003 Porto Alegre, RS, Brazil.

Email: taniafurlanetto@gmail.com
}

doi: http://dx.doi.org/10.4021/jmc778w glands outside the uterine cavity, usually ovaries, cul-de-sac, broad and uterosacral ligaments, and, less commonly, in the abdomen, thorax, brain and skin [1]. Thoracic endometriosis syndrome (TES) is a rare condition with four main presentations: pneumothorax, the most common, hemothorax, hemoptysis, and lung nodules. The diagnosis is usually established clinically when women have recurrent episodes of chest pain, dyspnea, and/or hemoptysis during menstruation. It is commonly associated with pelvic endometriosis [2-4].

Our aim is to describe an incidental diagnosis of pulmonary endometriosis in a 38 year-old patient who was admitted to treat acute pyelonephritis, and developed acute hypoxemia at night.

\section{Case Report}

A caucasian 38-year-old woman was admitted to hospital with a chief complaint of fever within the last 24 hours, a left sided lower back pain for 3 days, dysuria and nausea. She presented a previous episode of urinary tract infection one month ago and had a previous medical history of hypertension treated with ACE inhibitors since her second pregnan-

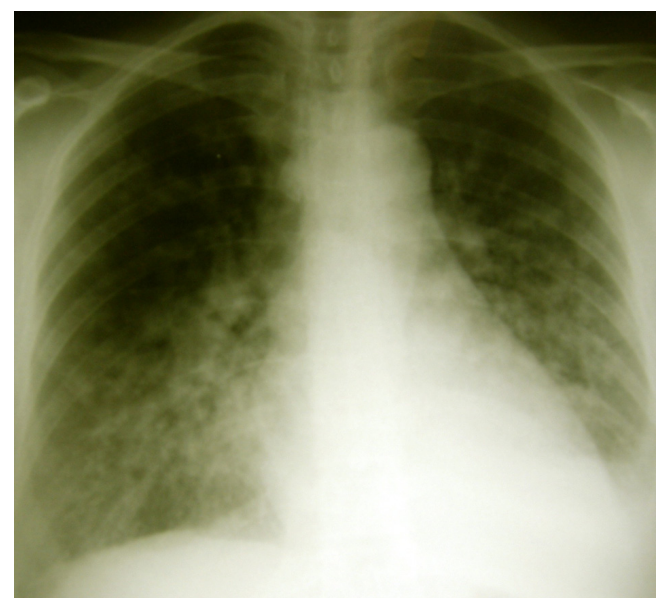

Figure 1. Thorax radiography with diffuse pulmonary infiltrates, and a small pleural effusion, in a patient with hypoxemia due to thoracic endometriosis. 


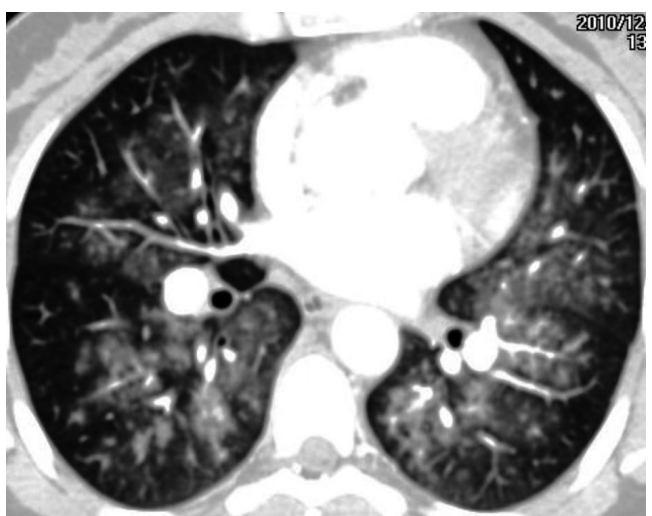

Figure 2. Lung CT with extensive areas of ground glass opacifications scattered predominantly in the medulla of both lungs in a patient with thoracic endometriosis, during the menstrual period.

cy. She had no other complaints and denied other previous medical problems. Left lumbar fist percussion was positive; otherwise her physical examination was normal. A urine sample had increased leucocytes, and erythrocytes. Blood hemoglobin was $10.6 \mathrm{~g} / \mathrm{dL}$ (normal range (NR) $12.0-16.0$ $\mathrm{g} / \mathrm{dL}$ ), blood leucocytes were 9,180 cells per $\mathrm{mL}$ (NR: 4,000 - 10,000 cells $/ \mathrm{mL}$ ), and serum creatinine level was $0.78 \mathrm{mg} /$ dL (NR: $0.5-1.2 \mathrm{mg} / \mathrm{dL}$ ). Urine grew Escherichia coli, and the ultrasound of her urinary tract had no abnormalities. Intravenous cefuroxime was initiated with resolution of symptoms. On the third day of hospitalization at 4:30 AM, during routine vital signs evaluation, oxygen saturation assessed by pulse oximetry was $70 \%$, and the respiratory rate (RR) was 26 respirations per minute. Oxygen was supplemented by nasal catheter, with improvement of oxygen saturation, and was discontinued at daytime. At 23:15 PM, her oxygen saturation assessed by pulse oximetry was $84 \%$. She was disoriented and complained of not feeling well, especially when lying down, with a productive cough of blood tinted sputum. She presented with tachypnea but denied dyspnea or chest pain. Arterial blood gases showed pH: 7.44 (NR 7.35 - 7.45); $\mathrm{pCO}_{2}: 32.3 \mathrm{mmHg}\left(\mathrm{NR} 35-45 \mathrm{mmHg}\right.$ ); $\mathrm{HCO}_{3}: 21.6 \mathrm{mEq} / \mathrm{L}$ (NR 22 - $26 \mathrm{mEq} / \mathrm{L}$ ); $\mathrm{pO}_{2}: 48.6 \mathrm{mmHg}$ (NR $80-100 \mathrm{mmHg}$ ), and $\mathrm{O}_{2}$ saturation: $86.7 \%$ (NR $95-100 \%$ ). This was improved with oxygen supplementation by Venturi mask, and arterial blood gases were $\mathrm{pH}: 7.44 ; \mathrm{pCO}_{2}: 36.0 \mathrm{mmHg} ; \mathrm{HCO}_{3}: 24.0$ $\mathrm{mEq} / \mathrm{L} ; \mathrm{pO}_{2}: 83.4 \mathrm{mmHg}$, and $\mathrm{O}_{2}$ saturation: $97.9 \%$. Her thoracic X-ray showed diffuse pulmonary infiltrates, and a small pleural effusion (Fig.1). The next morning, she informed that her period had begun one day ago, and recalled having epistaxis during her menstrual periods since menarche. She also recalled feeling unwell at night during her menstrual cycles, which were irregular, intensely painful, and had increased blood flow. On the sixth day of hospitalization, a chest CAT scan had no evidence of pulmonary thromboembolism, and showed extensive areas of ground glass opacifications scat-

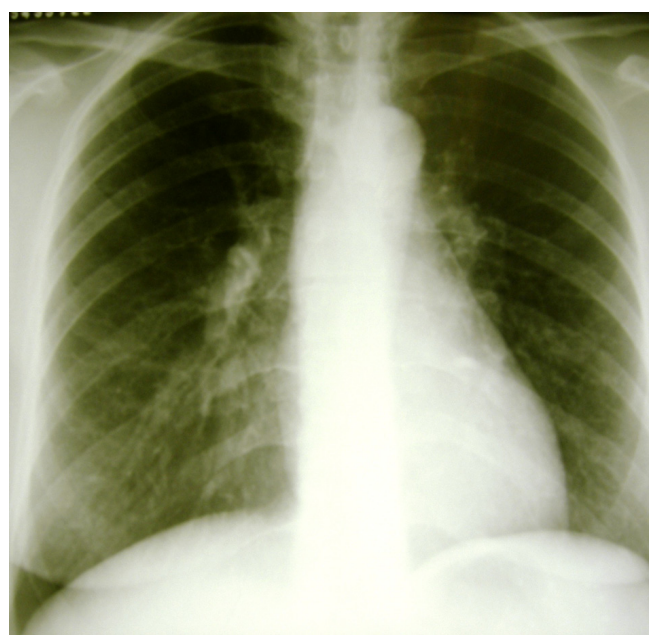

Figure 3. Thorax radiography after the end of the menstrual period in a patient with thoracic endometriosis.

tered predominantly in the medulla of both lungs (Fig. 2). On the seventh day of hospitalization, after the end of her menstrual bleeding, oxygen supplementation was discontinued, and hypoxemia did not recur. Upper airway endoscopic evaluation was performed and no abnormalities were found. A chest $x$-ray at the ninth day of hospitalization was normal (Fig. 3). The following day, a bronchoscopy with bronchoalveolar lavage was performed. The bronchial tree was macroscopically normal, and the bronchoalveolar fluid was negative for bacterial infection, tuberculosis, and fungus, and had macrophages $(85 \%)$, lymphocytes $(10 \%)$, neutrophils $(3 \%)$, eosinophils $(1 \%)$, and basophils $(1 \%)$. There were macrophages laden with hemosiderin. Peripheral lung and bronchial wall biopsy were normal. Cytology demonstrated small groups of cells in arrays compatible with endometrial cells, which confirmed the diagnosis of pulmonary endometriosis.

\section{Discussion}

A woman, with a long history of epistaxis and feeling unwell at night during her period, was hospitalized for pyelonephritis. Hypoxemia during the night led to the diagnosis of pulmonary endometriosis. Although the patient had severe hypoxemia, she did not ask for help, probably because she was asleep when it occurred, so hypoxemia was detected on routine evaluation. It would be expected that hypoxemia would have triggered awakening from sleep, nevertheless, severe oxygen desaturation does not always causes arousal from sleep $[5,6]$.

Once the abnormality in her blood oxygen levels followed the recumbent position at night, the source of bleeding probably was located in the low areas of her lungs, which allowed blood to spill to non-bleeding areas of the lungs, when recumbent. There was no evidence of hypoventilation, since 
the patient had tachypnea and hypocapnia. The increased A-an oxygen gradient suggested several mechanisms for hypoxemia. Infections, pulmonary thromboembolism, pulmonary congestion, and pulmonary interstitial metastasis were excluded by the clinical evolution. The cyclical character of her symptoms associated to menstrual flow, and blood tinted sputum, led to the clinical suspicion of pulmonary endometriosis.

Interestingly, the manifestations of TES, except for nodules, occurred more commonly in the right hemithorax, clearly an unexplained phenomenon that continues to elude all investigators [2,3]. Diagnosis is usually delayed until several episodes have occurred because of failure to associate the patient's symptoms with menses [7]. Computed tomography scan, unless obtained during menses, may be unremarkable [7]. Although histopathological detection of thoracic endometrial tissue is generally not required, diagnosis was established in some cases by pleural fluid cytology, needle biopsy of lung masses, and cytological study of bronchoscopic fluid [8-10]. On presentation, patients should be managed acutely as other patients with pneumothorax, hemothorax or hemoptysis. Once the patient has been stabilized, hormonal manipulation is generally recommended as the first line therapy, but recurrence rates are high. When hormonal therapy fails or is not tolerated, surgical therapies should be considered [7].

\section{Conclusion}

Pulmonary endometriosis should be considered in a patient who has unexplained episodes of nocturnal hypoxemia associated with hemoptysis, especially if there is periodicity.

\section{Acknowledgement}

We would like to thank the Grupo de Pesquisa e Pos-Graduacao-GPPG of Hospital de Clinicas de Porto Alegre for the support of this study.

\section{Conflict Interests}

The authors declare that they have no competing interests.

\section{References}

1. Giudice LC. Clinical practice. Endometriosis. N Engl J Med. 2010;362(25):2389-2398.

2. Joseph J, Sahn SA. Thoracic endometriosis syndrome: new observations from an analysis of 110 cases. Am J Med. 1996;100(2):164-170.

3. Channabasavaiah AD, Joseph JV. Thoracic endometriosis: revisiting the association between clinical presentation and thoracic pathology based on thoracoscopic findings in 110 patients. Medicine (Baltimore). 2010;89(3):183-188.

4. Alifano M, Trisolini R, Cancellieri A, Regnard JF. Thoracic endometriosis: current knowledge. Ann Thorac Surg. 2006;81(2):761-769.

5. Douglas NJ, White DP, Pickett CK, Weil JV, Zwillich CW. Respiration during sleep in normal man. Thorax. 1982;37(11):840-844.

6. Gothe B, Goldman MD, Cherniack NS, Mantey P. Effect of progressive hypoxia on breathing during sleep. Am Rev Respir Dis. 1982;126(1):97-102.

7. Augoulea A, Lambrinoudaki I, Christodoulakos G. Thoracic endometriosis syndrome. Respiration. 2008;75(1):113-119.

8. Zaatari GS, Gupta PK, Bhagavan BS, Jarboe BR. Cytopathology of pleural endometriosis. Acta Cytol. 1982;26(2):227-232.

9. Granberg I, Willems JS. Endometriosis of lung and pleura diagnosed by aspiration biopsy. Acta Cytol. 1977;21(2):295-297.

10. Wang HC, Kuo PH, Kuo SH, Luh KT. Catamenial hemoptysis from tracheobronchial endometriosis: reappraisal of diagnostic value of bronchoscopy and bronchial brush cytology. Chest. 2000;118(4):1205-1208. 